\title{
Effect of free radical altered IgG on allergic inflammation
}

\author{
S D HEWITT, J LUNEC, C J MORRIS, AND D R BLAKE
}

From the Department of Rheumatology, The Medical School, Birmingham University, Birmingham

SUMMARY The rheumatoid synovium is capable of producing large amounts of IgG which may become modified by the actions of free radicals. A rat model of synovitis was established and challenged with both normal and free radical altered IgG. IgG was prepared from homologousके pooled serum by high performance liquid chromatography, and free radical damage was inducedby 15 minutes ultraviolet (UV) irradiation. The results showed a worsening in gross assessmentso of inflammation, increases in biochemical indices of lipid peroxidation, and also a rise in theo proportion of IgG which, on reisolation, showed the characteristic fluorescence associated with 5 free radical damage. This demonstrated how the presence of free radical altered IgG might ${ }_{\zeta}^{-}$ convert an inflammatory insult to a more persistent stimulus, and the capacity of an environmento subjected to continuing antigenic stimulation to induce further free radical damage to IgG.

Key words: rheumatoid arthritis, immune complexes, neutrophils, rats, air pouch granulomas, lipid peroxidation, iron.

The rheumatoid synovial membrane is known to be capable of synthesising immunoglobulins in similar quantities to lymph nodes ${ }^{1}$; up to $60 \mathrm{mg}$ of $\mathrm{IgG}$ is synthesised a day. This is an important observation in the light of recent studies showing that human $\mathrm{IgG}$ is susceptible to free radical modification giving a characteristic fluorescent product. $^{2-4}$ Modifications of this type are believed to be a basic prerequisite for the formation of aggregates of $\mathrm{IgG}$, and their subsequent reaction with rheumatoid factors ${ }^{5}$ leads to the deposition of immune complexes. ${ }^{6}$ Phagocytosis of such complexes may lead to direct tissue damage by the release of lysosomal and other tissue degrading enzymes into synovial fluid. Also, immune complex stimulation promotes a respiratory burst in neutrophils and macrophages, ${ }^{78}$ many of which are present in the rheumatoid joint. This will result in the release of oxygen derived free radicals ${ }^{9}{ }^{10}$ in amounts sufficient to cause further tissue damage by peroxidation of membrane lipids. These peroxides may also further amplify the inflammatory response as they are chemotactic for neutrophils."

Tissue damage will also be caused indirectly after

Accepted for publication 21 May 1987.

Correspondence to Dr S D Hewitt, Department of Rheumatology, The Medical School, Birmingham University, Vincent Drive, Birmingham B15 2TJ. binding of complement by immune complexes, with consequent attraction of more neutrophilso increased vascular permeability, and enhanceő phagocytosis. Complement levels are depleted everi in early rheumatoid arthritis (RA), indicating the importance of the immune complex-complemeng interaction.

In this study we have used a self limiting model of allergic inflammation, the rat allergic air pouch, ${ }^{1.3}$ te test the hypothesis that autologous free radica $\bar{\alpha}$ altered, and therefore fluorescent, IgG may play ars important part in the conversion of transient to persistent chronic inflammation. This model use오 the delayed type hypersensitivity reaction to bovine serum albumin (BSA) ${ }^{14}$ in conjunction with an ai⿱ pouch to provide suitable space for induction of the inflammatory reaction. ${ }^{15}$ This enables quantitative assessments to be made of the exudative and proliferative processes, together with biochemical analysis of the exudate and histological analysis of the pouch wall.

The inflammatory reaction in this model wi⿺ resolve naturally over several weeks in the absence of repeated antigenic challenge or pro-inflammator stimulus such as blood injection. ${ }^{\text {th }}$ The cells which line the air pouch bear a close similarity to synovial cells, ${ }^{15}$ and we therefore suggest that the allergic air pouch is an appropriate synovial modesp 
for the study of the potential pro-inflammatory effects of free radical altered IgG.

\section{Materials and methods}

\section{A N IMAL MODEL}

BSA allergic air pouches were induced as described by Yoshino et al. ${ }^{13}$ Briefly, male Sprague Dawley rats, obtained from Bantin and Kingman (Hull, UK), weighing 200-250 g were grouped in sixes and sensitised by intradermal injection of BSA (Sigma, Poole, UK) emulsified with Freund's complete adjuvant (Difco, West Moseley, UK). Thirteen days after sensitisation rats received a dorsal, subcutaneous injection of $8 \mathrm{ml}$ air. Twenty four hours later the air pouch so formed was challenged with BSA in $2 \%$ carboxymethylcellulose (Sigma) in $0.9 \%$ saline solution with added antibiotics (benzylpenicillin (Glaxo, Greenford, UK) and streptomycin sulphate (Evans, Liverpool, UK)). To induce a more permanent inflammatory event in the air pouch animals received a further antigenic challenge (BSA in saline) five days after the initial injection of antigen into the air pouch. Animals were killed 1, 7, 14 , and 28 days after the antigenic challenge or rechallenge.

PREPARATION OF AUTOLOGOUS FREE

RADICAL ALTERED IgG

IgG was prepared from pooled homologous plasma by ammonium sulphate precipitation followed by purification of the precipitate containing the main immunoglobulin fraction by high performance liquid chromatography, using a TSK $3000 \mathrm{SW}$ column. The protein was eluted at $1 \mathrm{ml} / \mathrm{min}$ with physiological buffer $\left(0.067 \mathrm{M} \mathrm{KH}_{2} \mathrm{PO}_{4}+0.1 \mathrm{M} \mathrm{KCl}\right)$ as mobile phase. IgG was then dissolved in $40 \mathrm{mmol} / \mathrm{l}$ phosphate buffer and divided into two portions of equal volume. One half served as a control batch and received no further treatment (normal control IgG). The second portion was subjected to UV irradiation ( $366 \mathrm{~nm}, 254 \mathrm{~nm}$ source) for 15 minutes, a period insufficient to cause aggregation (free radical altered test $\mathrm{IgG}$ ). The immunoglobulin preparation was then further diluted with physiological buffer.

INTRODUCTION OF IgG INTO AIR POUCH BSA allergic air pouches were induced as described above. Normal or free radical altered IgG was injected into pouches in a $0.5 \mathrm{ml}$ volume at the time of challenge or rechallenge. The protein content of the IgG injections $(5 \mathrm{mg} / \mathrm{ml})$ was equivalent to $1 \mathrm{ml}$ injection of whole blood to parallel earlier experiments. ${ }^{16}$
ASSESSMENT OF INFLAMMATION

Animals were killed by exsanguination, their pouches were excised and drained of fluid exudate. Measurements were made of exudate volume, white cell count, and wet weight of granulation tissue. Blood and exudate were centrifuged, and samples of serum and cell free exudate were stored at $-20^{\circ} \mathrm{C}$.

\section{H IST OCHEMISTRY A N D}

I M M U NOH IS T OCH EM ISTRY

Samples of air pouch tissue were processed for both light and electron microscopy using standard laboratory schedules. Samples for light microscopy were fixed in formal-saline, dehydrated and paraffin wax embedded. Thin sections $(5 \mu \mathrm{m})$ were routinely stained with haematoxylin and eosin ( $\mathrm{H} \& \mathrm{E})$. Deposits of ferritin and ferric iron were demonstrated by the method described by Morris et al. ${ }^{18}$

Frozen sections were processed to visualise IgG by an indirect immunofluorescence technique. Primary serum was rabbit antirat IgG (Miles Laboratories, High Wycombe, UK) followed by fluorescein conjugated goat antirabbit IgG (Nordic, Maidenhead, UK). Sections were then examined using UV light.

\section{BIOCHEMICAL TESTS OF FREE RADICAL A C T IVITY}

Biochemical tests were performed on cell free exudates and sera to determine their extent of lipid peroxidation and the level of free radical damage sustained by reisolated IgG. Polyunsaturated fatty acids in biological membranes are susceptible to free radical induced peroxidation to give conjugated dienes which are broken down to malondialdehyde. The degree of lipid peroxidation of biological samples can be assessed by measuring the extent of diene conjugation, and the concentration of malondialdehyde indirectly by the amount of substances reacting with thiobarbituric acid (TBA).

TBA reactivity was measured by the method of Satoh. ${ }^{19}$ Protein was precipitated from a $0.5 \mathrm{ml}$ sample of cell free exudate or serum by the addition of $2.5 \mathrm{ml}$ of $10 \%$ trichloroacetic acid (Fisons, Loughborough, UK). The precipitate was washed with $0.05 \mathrm{M}$ sulphuric acid (BDH, Atherstone, UK) and then heated at boiling point for $30 \mathrm{~min}$ after the addition of $2.5 \mathrm{ml} 0.05 \mathrm{M}$ sulphuric acid (BDH) and $4 \mathrm{ml} 0.67 \%$ TBA (Sigma) made up in $2 \mathrm{M}$ sodium sulphate (Sigma). After cooling the pink chromogen was extracted with $4 \mathrm{ml}$ butanol and the absorbance of the organic layer was read with a Pye Unicam scanning spectrophotometer set at $532 \mathrm{~nm}$. Results are quoted as nmol of TBA reactive substances, calculated from a malondialdehyde standard curve. Diene conjugates were measured by the method 
of Lunec et al. ${ }^{20}$ Lipids were extracted from a $0.5 \mathrm{ml}$ sample of cell free exudate or serum using a mixture of chloroform and methanol (both spectroscopic grade, $\mathrm{BDH}$ ) in the ratio 2:1. After centrifugation the absorbance of the lower organic layer at $240 \mathrm{~nm}$ was taken as a direct indication of the extent of diene conjugation present in the sample.

IgG was reisolated from sera and cell free exudates by high performance liquid chromatography as described above. The extent of free radical damage to IgG was assessed by measuring its total fluorescence and dividing this by its total UV absorbance, to give a ratio of damaged (fluorescent) to total (UV absorbent) IgG. This may be described as an index of free radical damage to $\mathrm{IgG}$ and is represented as F/UV in figures.

STATISTICAL ANAIYSIS

All results are presented as the mean (SE) for each group. The data were parametric and were analysed by Student's $t$ test for significance at the $5 \%$ level.

\section{Results}

GROSS ASSESSMFNTS OF INFIAMMATION (Fig. 1)

The introduction of UV irradiated IgG into the BSA $\overrightarrow{\widetilde{D}}$ allergic air pouch caused an increase in exudation $\mathcal{O}$ and inflammatory cell infiltration after a single ores two antigenic challenges when compared with $\vec{\circ}$ normal IgG. These increases were most significant $7 \not$ to 14 days post challenge or rechallenge. After this $\vec{\omega}$ time the number of cells and volume of exudateo were significantly reduced in both test and controlō pouches. Fourteen days after a single antigenic $\vec{b}$ challenge the wet weight of granulation tissue was $\overrightarrow{-}$ significantly increased in animals receiving freeo radical altered IgG, though no significant differenceso were seen after two antigenic challenges.

\section{SiNGle ANtigenic challenge}
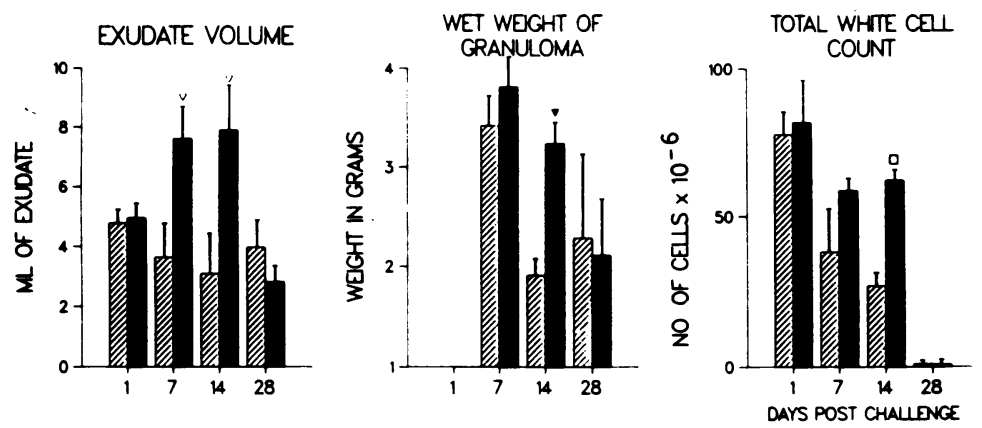

Fig. 1 Changes in exudate volume, wet weight of air pouch tissue, and total leucocvte coum with time (no measurement of granulation tissue was made at dav 1). $\nabla=p<0 \cdot 01$;

DOUBLE ANTIGENIC CHALLENGE $\square=p<0 \cdot 0.5 ; \quad \nabla=p<0 \cdot 001$.
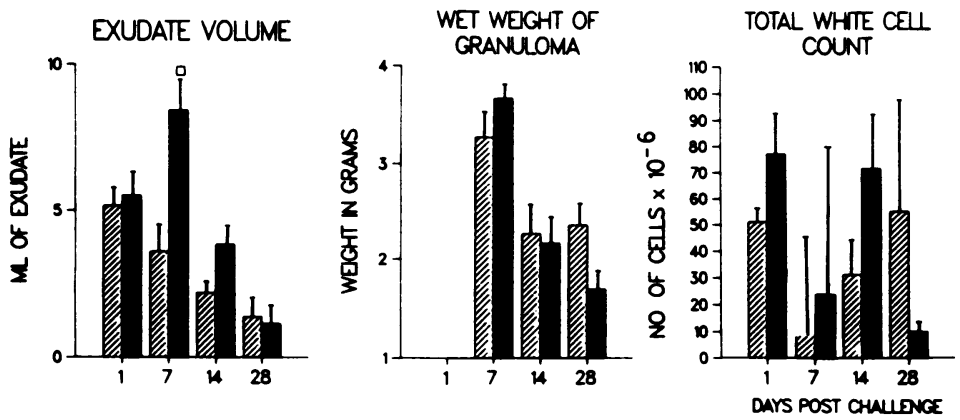

DZZA normal igg 
SINGLE ANTIGENIC CHALLENGE
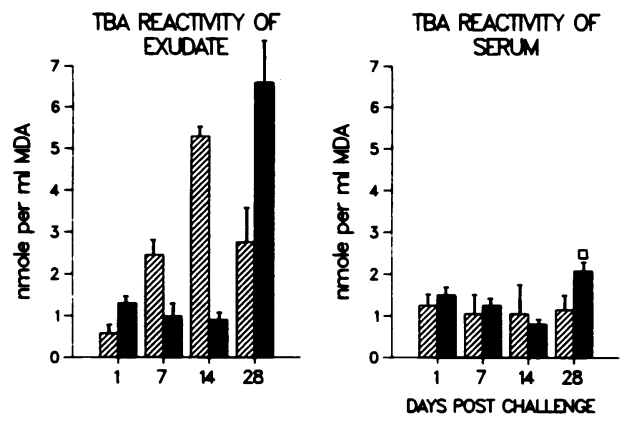

\section{DOUBLE ANTIGENIC CHALLENGE}
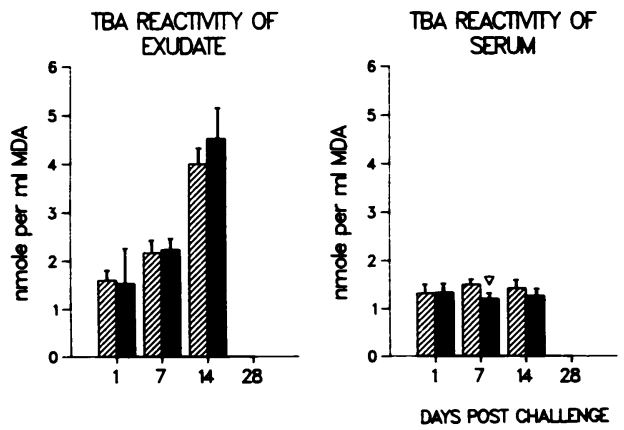

DPDarmal igo

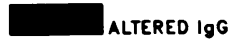

Fig. 2 Change in thiobarbituric acid (TBA) reactivity of serum and exudate with time. $\nabla=p<0.01 ; \square=p<0.05$. ( $M D A=$ malondialdehyde.)

B IOCHEMICAL TESTS (Figs 2 and 3)

The changes in TBA reactivity paralleled changes in the gross assessments of inflammation in that lipid peroxidation increased steadily during the experimental period. High levels of TBA reactive substances were more indicative of the chronic stages of the inflammatory reaction, being found throughout the double antigenic challenge experiment but only in the later stages of the single challenge experiment. Levels of TBA reactivity are not governed by exudate volume as, on correction for volume, the trend remained the same. TBA reactivity appears to be an indicator of local reactions of lipid peroxidation occurring within the air pouch, demonstrated by the uniform serum TBA reactivities.
The level of diene conjugates in exudates from the free radical altered IgG group was low or nil up to seven days after challenge or rechallenge. The reverse was true for serum diene conjugates, which traced a characteristic acute phase curve, the pattern of which was shifted back by five days in the double antigenic challenge experiment. In the early part of the single challenge experiment serum levels of diene conjugates were significantly higher in test animals than in control animals, though there was not such a sharp distinction between these two groups in the double challenge experiment.

Sera from rats that received free radical altered IgG after a single antigenic challenge showed little change (relative to controls) in the index of free radical damage to reisolated IgG throughout the experiment. Each of the other fluids examined from this group, i.e., exudate produced after a single antigenic challenge, and exudate and sera collected after two antigenic challenges, showed an upward trend over the 28 day experimental period. This trend was most marked in the exudate of rats which had received two antigenic challenges, though the increase over control values was not significant. The levels of fluorescent IgG were always higher in exudates than in sera, correlating with TBA reactivity results rather than diene conjugate data. The most important aspect of this result is the increase in sera of the index of free radical damage to $\mathrm{IgG}$, which followed the upward trend seen in the exudate after a single antigenic challenge and injection of free radical altered IgG. This pattern of raised levels of free radical altered $\mathrm{IgG}$ in serum has also been seen in rheumatoid patients with high levels of free radical altered IgG in their synovial fluid. ${ }^{+}$

\section{H I S T O L O G Y}

In the single challenge experiment, pouches that had received free radical altered IgG showed an increase in cellularity and vascularity of test pouches in the early stages compared with those that had received normal IgG, the end result being a greater thickness of granulation tissue (Fig. 4).

After two antigenic challenges pouches injected with free radical altered IgG showed a highly ordered connective tissue matrix with a very active cellular lining layer (Fig. 5). Pouches challenged with normal IgG showed a barely distinguishable lining layer with a decreased thickness of organised tissue in later stages (Fig. 6).

HISTOCHEMISTRY AND

I M MUNOH ISTOCHEMISTRY

(Tables 1 and 2)

Ferritin containing cells, presumably macrophages, 


\section{Single antigenic challenge double antigenic Challenge}
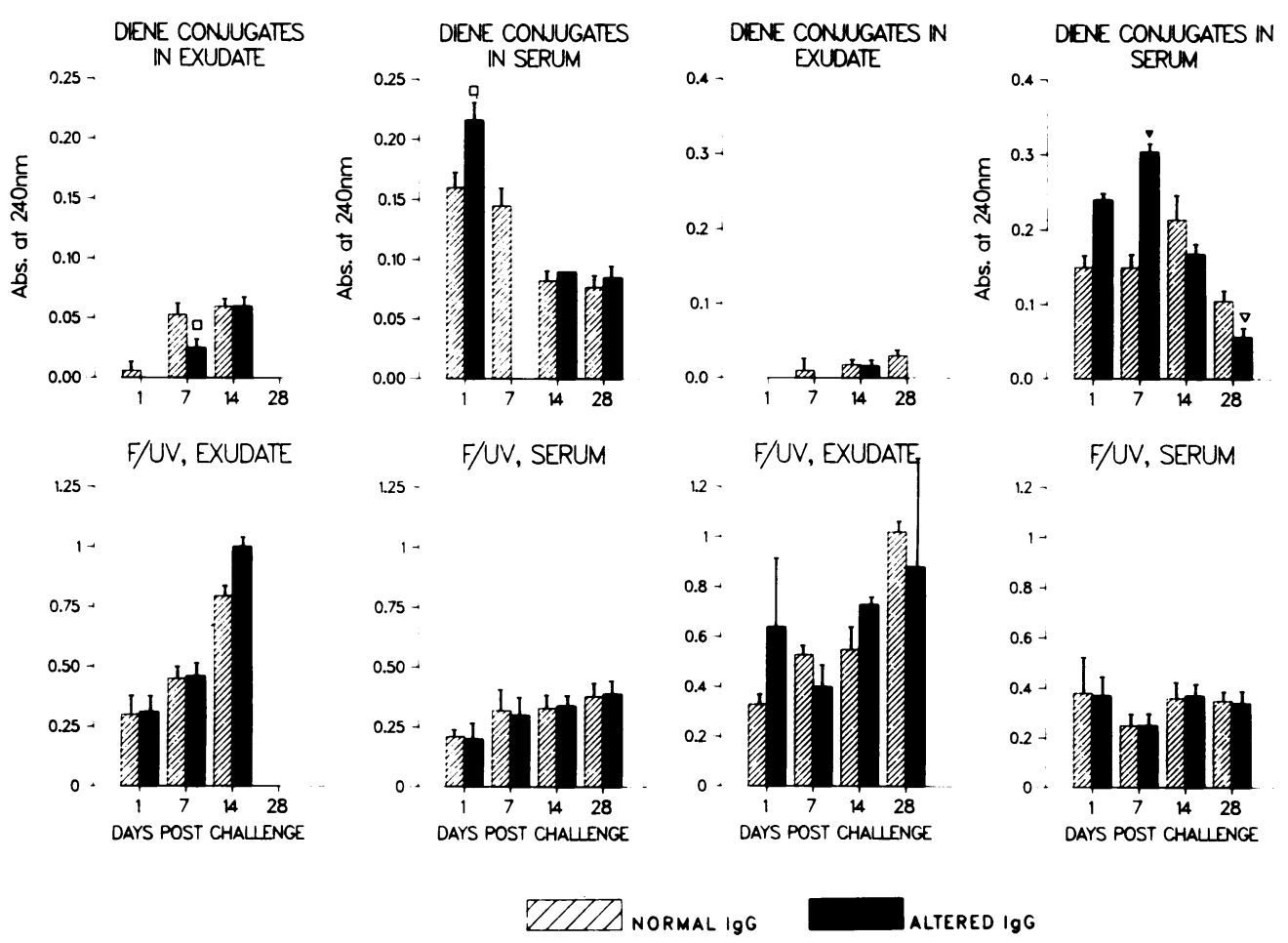

Fig. 3 Levels of diene conjugates and fluorescent (free radical damaged) $\lg G$ in serum and exudate at different stages of inflammatory reaction. $\nabla=p<0 \cdot(01 ; \square=p<0 \cdot(05 ; \quad \nabla=p<0 \cdot(001$. ( F/UV = ratio of damaged (fluorescent) to total (UV absorbent) $\lg G$.)

were demonstrated in all sections by an immunoperoxidase technique. After a single antigenic challenge the number of positively" staining cells in control pouches was significantly greater than the number in test pouches at all time points. Such positively stained cells were not associated with ferric iron, as demonstrated by Perls' technique, and were deemed to contain apoferritin.

On days 7 and 28 after two antigenic challenges the number of immunohistochemically positive cells was slightly increased, though more positive cells were found in control pouches than in those treated with free radical altered IgG. The reverse, however, was true on day 14 . Cells which reacted positively to Perls' stain for iron were seen in test pouches throughout the double antigenic challenge experiment and in control pouches on day 28 . The codistribution of Perls' and ferritin staining patterns indicates the presence of iron loaded ferritin within these cells. Control tissue contained iron loaded ferritin only in the later stages of the experiment, whereas tissue taken from pouches challenged with

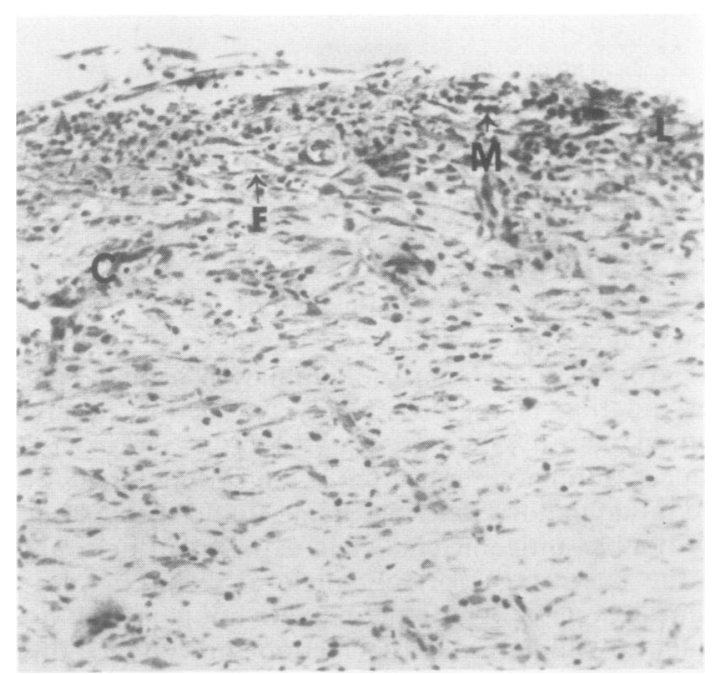

Fig. 4 Air pouch tissue, $H \& E$, day 14, single challenge free radical altered $\operatorname{Ig} G$. Lumen of pouch at top, showing fibroblastoid cells $(F)$, macrophages $(M)$, active lining cell laver (L) four to five cells deep, and capillaries (C). 


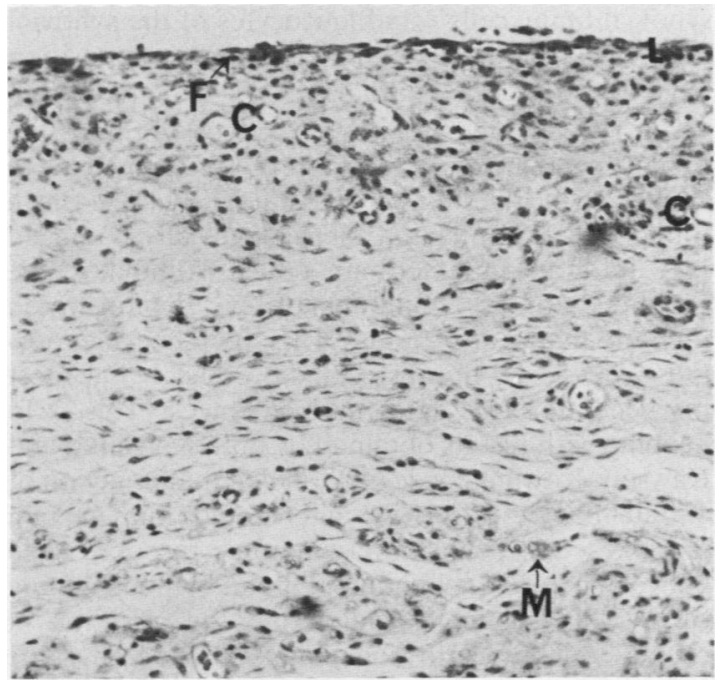

Fig. 5 Air pouch tissue, $H \& E$, day 14, double challenge, free radical altered IgG. Lumen of pouch at top, showing fibroblastoid cells $(F)$, foamy macrophages $(M)$, and many capillaries $(C)$ within organised connective tissue. The lining cell layer $(L)$ is relatively thin.

free radical altered IgG showed positive Perls' staining at all times after two antigenic challenges.

I M M U NOFLUORE S C E N C E

IgG was demonstrated in tissue from air pouches which had received two antigenic challenges. Initially (day 7), staining was restricted to test

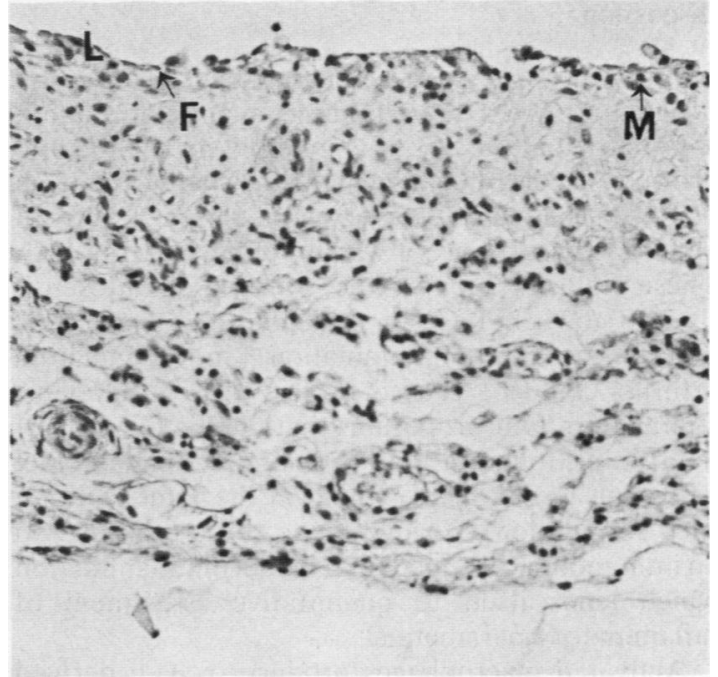

Fig. 6 Air pouch tissue, $H \& E$, day 14, double challenge, normal IgG. Lumen at top. This resolving pouch shows reduced thickness and cellularity with macrophages $(M)$, fibroblasts $(F)$, and discontinuous lining cell layer $(L)$ only two cells deep.

pouches in the region of small capillaries; control pouches showed no fluorescent staining until day 14 . As the inflammatory reaction progressed both the extent and intensity of the fluorescence increased until at day 28 generalised staining was seen both in pouches that had received free radical altered IgG and those that had received normal IgG.

Table 1 Numbers of air pouch cells staining positively for ferritin using an immunohistochemical technique

\begin{tabular}{|c|c|c|c|c|c|c|}
\hline & \multicolumn{3}{|c|}{ Single challenge } & \multicolumn{3}{|c|}{ Double challenge } \\
\hline & Day 7 & Day 14 & Day 28 & Day 7 & Day 14 & Dav 28 \\
\hline $\mathrm{NIgG \dagger}$ & $6 \cdot 8(1.4)$ & $11 \cdot 5(2 \cdot 2)$ & $5 \cdot 3(1 \cdot 5)$ & $8 \cdot 7(2 \cdot 2)$ & $3 \cdot 6(1 \cdot 0)$ & $7 \cdot 5(2 \cdot 6)$ \\
\hline FRIgG† & $3.7(0 \cdot 6)^{*}$ & $5.8(1.4)^{*}$ & $0^{*}$ & $7.8(1.9)$ & $6 \cdot 6(2 \cdot 0)$ & $4.9(0.8)$ \\
\hline
\end{tabular}

Mean number (SE) of positive cells in 12 random ficlds.

*Statistically significant in comparison with corresponding NIgG values, $\mathrm{p}<0 \cdot 05$.

$+\mathrm{NIgG}=$ normal IgG: $\mathrm{FRIgG}=$ frec radical altered IgG.

Table 2 Numbers of air pouches staining positively with Perls' stain for ferric iron

\begin{tabular}{|c|c|c|c|c|c|c|}
\hline & \multicolumn{3}{|c|}{ Single challenge } & \multicolumn{3}{|c|}{ Double challenge } \\
\hline & Day 7 & Day 14 & Day 28 & Day 7 & Day 14 & Day 28 \\
\hline $\begin{array}{l}\text { NIgG } \\
\text { FRIgG }\end{array}$ & $\begin{array}{l}0 \cdot 8(0 \cdot 7) \\
0\end{array}$ & $\begin{array}{l}0 \\
0\end{array}$ & $\begin{array}{l}0 \\
0\end{array}$ & $\begin{array}{l}0 \\
4(1.9)\end{array}$ & $\begin{array}{l}0 \\
1 \cdot 1(0 \cdot 7)\end{array}$ & $\begin{array}{l}1.4(0.5) \\
1.3(0.4)\end{array}$ \\
\hline
\end{tabular}

Mean number (SE) of positive cells in 12 random fields. 


\section{Discussion}

Several lines of evidence suggest that denaturation of IgG may give rise to immune complex formation and perpetuation of inflammation in rheumatoid arthritis, the most convincing being that virtually all of these patients present with raised levels of antibodies in their sera which are specific for IgG. These findings support the concept of autosensitisation to 'self IgG' in rheumatoid disease. Persistent synovial inflammation in rheumatoid arthritis could be caused by this type of antigenic stimulation. Our proposal is that the high density of neutrophils found in RA synovial fluid may interact with high levels of IgG found in the joint to cause such stimulation. To investigate this we have used an immunologically mediated model of inflammation which lends itself to quantitative assessment of inflammatory parameters.

Activated macrophages produce oxygen derived free radicals. ${ }^{7}$ Cell surface stimulation by particulate materials or soluble inflammatory mediators will provoke a respiratory burst in neutrophils which will also result in the production of oxygen derived radicals. $^{21-25}$ These highly reactive species have the potential to oxidise lipids ${ }^{11}$ and denature proteins $^{26}$ and many other types of biomolecule ${ }^{27}$. It is suggested that neutrophils and macrophages produce free radicals on stimulation, leading to damage to IgG. ${ }^{910}$

There is increased production of IgG in rheumatoid disease, ${ }^{1}$ but only $9 \%$ of it is found as rheumatoid factor ${ }^{28}$ the rest may have some other antigenic specificity. Fresh rheumatoid synovial fluid and sera contain fluorescent products similar to those seen on free radical damage to IgG. ${ }^{4}$ Rheumatoid factor has greater reactivity with denatured monomeric and aggregated IgG than with normal IgG ${ }^{29}$ so damage to IgG will lead to a greater degree of complex formation. The $15 \mathrm{~min}$ irradiation period used in these experiments produced mainly fluorescent monomeric denatured IgG. There was always more fluorescence in air pouch exudate than in the corresponding sera, indicating that the fluorescent IgG was probably locally produced, in contrast with the diene conjugate results for serum specimens, which appear to reflect a systemic reaction to the inflammatory insult. Diene conjugates have previously been shown to correlate with the levels of acute phase reactants in rheumatoid sera. ${ }^{20}$ Here they trace a characteristic acute phase curve whose peak occurs at day 7 in the single antigenic challenge experiment and day 1 in the double challenge experiment. Immune complexes containing IgG have been demonstrated in synovial fluid ${ }^{30} 31$ and also within synovial lining cells ${ }^{32}$ and leucocytes of the synovial fluid. ${ }^{33}$ The effects of immune complex deposition have been described earlier.

Our results in the rat air pouch support the hypothesis that free radical altered IgG may have a key role in rheumatoid inflammation. We have found that the injection of free radically damaged $\overrightarrow{\mathbb{D}}$ IgG into an inflamed air pouch stimulates the $\varrho$ production of larger amounts of IgG, demonstrated is in both tissue and fluids. This IgG became pro- $\vec{\circ}$ gressively more fluorescent, the effect being most marked after two antigenic challenges. This is in $\vec{\omega}$ keeping with results obtained by both Kowanko and Rawson. Kowanko et al have shown that injection of $\bar{a}$ an air pouch with heat aggregated human $\operatorname{IgG}$ के provokes an acute inflammatory response and $-\overrightarrow{-}$ phagocytosis of the immunoglobulin by pouch lining cells. ${ }^{34}$ Rawson et al found that the injection of $\stackrel{\circ}{\circ}$ rheumatoid IgG into knee joints elicited an acute 을 inflammatory response in patients with RA. ${ }^{35}$ The injection of normal $\mathrm{IgG}$ initiated only a mild $Z$ inflammatory reaction in one patient.

IgG reisolated from control pouches which had $\stackrel{\Phi}{\rightrightarrows}$ received two antigenic challenges showed a pro- $\underset{\mathbb{\Phi}}{ }$ gressive increase in the formation of fluorescent IgG, though the absolute values were lower tha $\oplus$ those obtained with IgG reisolated from test. pouches. This suggests that supplying a suitable IgG substrate to an environment already actively generating free radicals results in the type of chain reaction that leads to neutrophil stimulation and immune complex formation. ${ }^{4}$

Diene conjugates are an early indicator of lipid $\overrightarrow{\overrightarrow{0}}$ peroxidation; their levels fall as they undergo $\exists$ further peroxidation reactions to form end products that are detectable by the TBA test. Therefore our negative results may indicate one of two things; either there has been no lipid peroxidation so no diene conjugates have been formed or there has 3 been vigorous catalysis of lipid peroxidation reactions, resulting in the conversion of diene conjugates to substances further down the peroxidative chain. The latter appears to be true in 9 these experiments as early low values for diene $D$ conjugates were followed by high TBA reactivity values later in the experiment, indicating progressive $\stackrel{N}{N}$ peroxidation reactions.

In general, after two antigenic challenges the $\mathcal{O}$ pattern of increased exudation, white cell count, TBA reactivity, and low levels of diene conjugates in exudates from pouches that had received free $\stackrel{\varrho}{C}$ radical altered IgG was mirrored by control exu- $\stackrel{D}{\oplus}$ dates. This was not the case after a single antigenic ? challenge when free radical altered IgG had proinflammatory effects compared with normal IgG. 
The results therefore show how the presence of free radical damaged IgG could convert an acute inflammatory insult (single antigenic challenge) to a more persistent stimulus and also how continued antigenic stimulation (two antigenic challenges) sets up a system with enough momentum to induce damage to any normal IgG within the local environment, be it joint or air pouch.

The index of free radical damage to $\mathrm{IgG}$ was seen to rise in test group exudates after two antigenic challenges and this group also showed an associated rise in this index in the sera. This type of systemic effect has also been seen in rheumatoid patients who show high levels of free radical altered IgG in their synovial fluid associated with raised levels in their sera. ${ }^{+}$This, together with the serum diene conjugate data, suggests that the model may be developed further to examine some of the systemic effects associated with rheumatoid disease.

Further work will examine the persistence of inflammation beyond 28 days in pouches challenged with free radical altered IgG. In an attempt to overcome the problems of low exudate volumes at this stage it is hoped that IgG may be isolated from the granulomatous pouch wall and assayed for free radical damage.

By using a naturally remitting model of inflammation, challenged with free radical altered IgG, we have a system which, we believe, mimics the type of chronic antigenic stimulation necessary for the persistence of rheumatoid inflammation.

We are grateful to Miss S J McCleary (Selly Oak Hospital, Birmingham) for carrying out biochemical analysis and to $\mathrm{Mr} \mathrm{A} \mathrm{C}$ Wainwright (Department of Rheumatology) for the immunohistochemistry. SDH/DRB are funded by the British Technology Group and CJM/DRB by the Arthritis and Rheumatism Council for Research: DRB is also supported by Ciba Geigy.

\section{References}

1 Smiley J D. Sachs C. Ziff $M$. In vitro synthesis of immunoglobulins by rheumatoid synovial membranc. J Clin Invest 1968: 47: 624-32.

2 Wickens D G. Graff T L. Lunec J. Dormandy T L. Free radical mediated aggregation of human gamma globulin. Agents Actions 1981: 11: 650-1.

3 Wickens D G. Norden A G. Lunec J. Dormandy T L. Fluorescence changes in human gamma globulin induced by frec radical activity. Biochim Biophys Acta 1983: 742: 607-16.

4 Lunec J. Blake D R. McCleary S J. Brailsford S. Bacon P A. Self perpetuating mechanisms of immunoglobulin $G$ aggregation in rhcumatoid inflammation. J Clin Invest 1985: 76: 2084-90).

5 Johnson P M. Watkins J. Holborow E J. Antiglobulin production to altered IgG in rheumatoid arthritis. Lancet 1975; i: $611-4$.

6 Hannestad K. The presence of aggregated gamma globulin in certain rheumatoid synovial effusions. Clin Exp Immunol 1967; 2: $511-29$.
7 Johnston R B. Godzik C A. Cohn Z A. Increased superoxide production by immunologically activated and chemically clicited macrophages. J Exp Med 1978: 148: 115-27.

8 Goldstein I M. Roos D. Kaplan H B. Weissmann G. Complement and immunoglobulins stimulate superoxide production by human lcucocytes independently of phagocytosis. J Clin Invest 1975: 56: 1155-63.

9 McCord $\mathrm{J} \mathrm{M}$. Frec radicals and inflammation: protection of synovial fluid by superoxide dismutase. Science 1974; 185: 529-31.

10 Fantone J C. Ward P A. Role of oxygen derived free radicals and metabolites in leucocyte dependent inflammatory reactions. Am J Pathol 1982: 107: 397-418.

11 Petrone W F. English D K. Wong K. McCord J M. Free radicals and inflammation in superoxide dependent activation of a neutrophil chemotactic factor in plasma. Proc Natl Acad Sci USA 1980; 77: 1159-63.

12 Bianco N E. Dobkin L W. Schur P H. Immunological properties of isolated IgG and IgM anti gamma globulins (rheumatoid factors). Clin Exp Immunol 1974; 17: 91-101.

13 Yoshino S. Bacon P A. Blake D R. Wainwright A C. Walton $\mathrm{KW}$. A model of persistent antigen induced chronic inflammation in the rat air pouch. Br J Exp Pathol 1984; 65: 201-14.

14 Ohuchi K. Yoshino S. Kurihara A. et al. Delayed type hypersensitivity as revealed on the footpads of mice to azobenzenearsonate-acetyl bovine serum albumin. Int Arch Allergy Appl Immunol 1981; 66: 391-403.

15 Tsurufuji S. Yoshino S. Ohuchi K. Induction of an allergic air pouch inflammation in rats. Int Arch Allergy Appl Immunol 1982; 69: 189-98.

16 Yoshino S. Blake D R. Hewitt S. Morris C. Bacon P A. Effect of blood on the activity and persistence of antigen induced inflammation in the rat air pouch. Ann Rheum Dis 1985: 44: 485-90.

17 Edwards J C W. Sedgwick A D. Willoughby D A. The formation of a structure with the features of a synovial lining by subcutaneous injection of air: an in vivo tissue culture system. $J$ Pathol 1981; 134: 147-56.

18 Morris C J. Wainwright A C. Steven M M. Blake D R. The nature of iron deposits in hacmophilic synovitis. An immunohistochemical. ultrastructural and x-ray microanalytical study. Virchows Arch /A/ 1984; 404: 75-85.

19 Satoh K. Serum lipid peroxide in cerebrovascular disorders determined by a new colorimetric method. Clin Chim Acta 1978: 90: 37-43.

20 Lunce J. Halloran S P. White A G. Dormandy T L. Free radical oxidation (peroxidation) products in serum and synovial fluid. $J$ Rheumatol 1981: 8: 233-45.

21 Babior B H. Kipnes R S, Curnutte J T. Biological defence mechanisms. The production by leucocytes of superoxide, a potential bactericidal agent. J Clin Invest 1973; 52: 741-4.

22 Salin M L. McCord J M. Free radicals and inflammation. J Clin Invest 1975; 56: 1319-23.

23 Weiss S J, Rustagi P K, LoBuglio A F. Human granulocyte generation of hydroxyl radical. J Exp Med 1978; 147: 316-23.

24 Tauber A I, Gabig T G, Babior B H. Evidence for production of oxidising radicals by the particulate $\mathrm{O}_{2}^{-}$forming system from human neutrophils. Blood 1979: 53: 666-76.

25 Takanaka K. O'Brien P J. Generation of activated oxygen species by polymorphonuclear leucocytes. FEBS Lett 1980; 110: 283-6.

26 Henriksen T, Melo T B, Saxebol G. Free radical formation in proteins and protection from radiation damage. In: Pryor W A, ed. Free radicals in biology. Vol. II. New York: Academic Press, 1976: 213-56.

27 Henriksen T. Bergene R, Heiber A, Sagstuen E. Radical reactions in nucleic acids: crystal systems. In: Pryor W A, ed. Free radicals in biology. Vol. II. New York: Academic Press, 1976: 257-94. 
28 Hoffman W L. Douglass R R. Smiley J D. Synthesis of electrophoretically restricted IgG by cultured rheumatoid synovium. Arthritis Rheum 1984: 27: 976-84.

29 Winchester R J. Agnello V. Kunkel H G. Gamma globulin complexes in synovial fluids of patients with rhcumatoid arthritis. Partial characterisation and relationship to lowered complement levels. Clin Exp Immunol 1970: 6: 689-706.

30 Kunkel H G. Muller-Eberhard H J. Fudenberg H H. Tomasi T B. Gamma globulin complexes in rheumatoid arthritis and certain other conditions. J Clin Invest 1961: 40: 117-29.

31 Baumal R. Broder I. Studies into the occurrence of soluble antigen-antibody complexes in disease. III. Rheumatoid arthritis and other human diseases. Clin Exp Immunol 1968: 3: $555-69$
32 Kinsella T D. Baum J. Ziff M. Studies of isolated synovial lining cells of rhcumatoid and non rheumatoid synovial membranes. Arthritis Rheum 1970: 13: 734-53.

33 McDuffic F C. Immune complexes in the rheumatic diseases. J Allergy Clin Immunol 1978; 62: 37-43.

34 Kowanko I C. Gordon T P. Rozenbilds M A M. Brookes P M. Roberts-Thompson P J. The subcutancous air pouch model of synovium and the inflammatory response to heat aggregated gammaglobulin. Agents Actions 1986: 18: 421-8.

35 Rawson A J. Hollander J L. Quismorio F P. Abelson N M. 0 Experimental arthritis in man and rabbit dependent on serum anti immunoglobulin factors. Ann NY Acad Sci 1969: 30: $\overrightarrow{0}$ $188-93$. 